\title{
NEOPLASIA MALIGNA DO ENCÉFALO NO PARANÁ-BRASIL, INCIDÊNCIA SOBRE INTERNAÇÕES E ÓBITOS
}

\author{
MALIGNA NEOPLASIA OF THE ENCEPHALUS IN PARANÁ-BRAZIL, \\ INCIDENCE ON HOSPITALIZATIONS AND DEATHS
}

Emanoelle Aparecida Palangani ${ }^{*}$, Patricia Dias Rabelo ${ }^{1}$, Jéssica Almeida Dall'Asta ${ }^{1}$, Sandro Artur Veit Bublit ${ }^{2}$, Rafaela Silva Waltrick ${ }^{3}$.

'UNINGÁ - Centro Universitário Ingá, Maringá, PR, Brasil.

Universidade Cesumar, Maringá, PR, Brasil.

'Universidade do Vale do Itajaí, Itajai, SC, Brasil.

*manupalangani@gmail.com

\section{RESUMO}

A neoplasia maligna do encéfalo, é um tipo de tumor cerebral, sendo uma porção de células anormais originadas dentro do tecido cerebral. As complicações dessa condição dependem da localização do tumor. Algumas delas podem se formar na presença de outro câncer não diagnosticado. Nesse estudo foi feito a avaliação da incidência de internações e óbitos de neoplasia maligna do encéfalo no estado do Paraná-Brasil, entre as faixas etárias 50 a 80 anos e mais, na faixa temporal de 2014 a 2019, assim como, a predominância entre os sexos. Houve a coleta e análise de dados do DATASUS, recorrendo ao intervalo de tempo entre 2014 a 2019. Como critério de inclusão analisou-se os conteúdos de internação e óbitos, nas faixas etárias de 50 a 80 anos e mais, além dos sexos, foi realizado cálculo de extremos. Em consideração ao número de internações da neoplasia maligna do encéfalo na faixa de 50 a 59 anos, o sexo masculino apresenta, entre 2014 (68) e 2019 (128), aumento em 88,24\%, o sexo feminino entre 2014 (92) e 2019 (138), teve aumento de 50\%; analisando a idade de 60 a 69 anos no sexo masculino entre 2014 (84) e 2019 (144), ha aumento em $71,43 \%$, já o sexo feminino, entre 2014 (75) e 2019 (145) aumentou 93,33\%; a faixa etária de 70 a 79 anos, o sexo masculino, apresenta entre 2014 (53) e 2019 (64), aumento em 20,74\%, já o sexo feminino, nessa faixa etária, entre 2014 (44) e 2019 (82) apresentou aumento em $86,36 \%$. A faixa etária 80 e mais, no sexo masculino, em 2014 (12) e no ano de 2019 (15), aumentou em 25\% Analisando o sexo feminino, nessa faixa etária, entre 2014 (14) e 2019 (23) ha um aumento em $64,29 \%$. Sobre a análise de óbitos entre a faixa etária de 50 a 59 anos, o sexo masculino apresenta entre 2014 (15) e 2019 (22) aumento em 46,67\%; enquanto, o sexo feminino na mesma faixa etária, entre 2014 (20) e 2019 (17) diminuiu em 15\%. Na próxima faixa etária, de 60 a 69 anos, analisando o sexo masculino, entre 2014 (19) e 2019 (21) apresentou aumento em 10,53\%. No sexo feminino, na mesma faixa etária, 2014 (18) até 2019 (19) aumentou 5,56\%. Assim, entre 70 e 79 anos, o sexo masculino entre 2014 (15) e 2019 (12), diminuiu $20 \%$ e no sexo feminino, nesta faixa etária o ano de 2014 (9) e 2019 (11), aumentam em $22,22 \%$. Enquanto a faixa etária de 80 anos e mais, no sexo masculino em 2014 (4) e 2019 (5) verificou-se um aumento em 25\%; sobre o sexo feminino, essa idade não apresenta, entre 2014 (3) e 2019 (3), alteração. Conclui-se, que em ambos os sexos, no período de 2014 a 2019, em todas as 
faixas etárias houve aumento nas porcentagens de internação por neoplasias malignas de encéfalo. Em relação ao óbito pela doença, o maior percentual de aumento foi visto no sexo masculino entre 50 a 59 anos, reduzindo o numero de óbitos desse sexo apenas entre 70 e 79 anos. Comparando os sexos, as mulheres apresentaram menor taxa de aumento de óbito que os homens, reduzindo entre 50 a 59 anos e se mantendo constante na população com 80 anos e mais, enquanto que no sexo masculino a única redução de óbitos foi entre 70 a 79 anos.

Palavras-chave: Encefálo. Epidemiologia. Neoplasias encefálica. Neoplasias malignas. Neurociências. 